\title{
Effects of thermal stress on amount, composition, and antibacterial properties of coral mucus
}

\author{
Rachel M Wright ${ }^{\text {Corresp., }}{ }^{1,2}$, Marie E Strader ${ }^{2,3}$, Heather M Genuise ${ }^{2}$, Mikhail V Matz ${ }^{2}$ \\ 1 Department of Genetics, Harvard Medical School, Boston, MA, United States \\ 2 Department of Integrative Biology, University of Texas at Austin, Austin, TX, United States \\ 3 Department of Ecology, Evolution, and Marine Biology, University of California, Santa Barbara, Santa Barbara, CA, United States \\ Corresponding Author: Rachel M Wright \\ Email address: rachel_wright@hms.harvard.edu
}

The surface mucus layer of reef-building corals supports feeding, sediment clearing, and protection from pathogenic invaders. As much as half of the fixed carbon supplied by the corals' photosynthetic symbionts is incorporated into expelled mucus. It is therefore reasonable to expect that coral bleaching (disruption of the coral-algal symbiosis) would affect mucus production. Since coral mucus serves as an important nutrient source for the entire reef community, this could have substantial ecosystem-wide consequences. In this study, we examined the effects of heat stress-induced coral bleaching on the composition and antibacterial properties of coral mucus. In a controlled laboratory thermal challenge, stressed corals produced mucus with higher protein $(\beta=2.1, p<0.001)$ and lipid content $(\beta=15.7, p=0.02$ ) and increased antibacterial activity (likelihood ratio $=100, p<0.001$ ) relative to clonal controls. These results are likely explained by the expelled symbionts in the mucus of bleached individuals. Our study suggests that coral bleaching could immediately impact the nutrient flux in the coral reef ecosystem via its effect on coral mucus. 
1 Effects of thermal stress on amount, composition, and antibacterial properties of coral mucus 2

3 Rachel M. Wright ${ }^{1,2 *}$, Marie E. Strader ${ }^{2,3}$, Heather M. Genuise ${ }^{2}$, Mikhail V. Matz ${ }^{2}$

4

5 1. Department of Genetics, Harvard Medical School

6 2. Department of Integrative Biology

7 3. Department of Ecology, Evolution, and Marine Biology

8

9 *Corresponding author: Rachel M. Wright

10 Email: rachelwright8@gmail.com

11

12 


\section{ABSTRACT}

14 The surface mucus layer of reef-building corals supports feeding, sediment clearing, and

15 protection from pathogenic invaders. As much as half of the fixed carbon supplied by the corals'

16 photosynthetic symbionts is incorporated into expelled mucus. It is therefore reasonable to

17 expect that coral bleaching (disruption of the coral-algal symbiosis) would

18 affect mucus production. Since coral mucus serves as an important nutrient source for the entire

19 reef community, this could have substantial ecosystem-wide consequences. In this study, we

20 examined the effects of heat stress-induced coral bleaching on the composition and antibacterial

21 properties of coral mucus. In a controlled laboratory thermal challenge, stressed corals

22 produced mucus with higher protein $(\beta=2.1, \mathrm{p}<0.001)$ and lipid content $(\beta=15.7, \mathrm{p}=0.02)$

23 and increased antibacterial activity (likelihood ratio $=100, \mathrm{p}<0.001$ ) relative to clonal controls.

24 These results are likely explained by the expelled symbionts in the mucus of bleached

25 individuals. Our study suggests that coral bleaching could immediately impact the nutrient flux

26 in the coral reef ecosystem via its effect on coral mucus. 


\section{INTRODUCTION}

Rising sea surface temperature has increased the global risk of coral bleaching, the breakdown of the symbiosis between a coral host and its algal symbiont, to alarming levels (Hughes et al., 2018). The direct impacts of bleaching on the animal host and algal symbiont are well studied. For example, coral bleaching has been shown to downregulate the expression of genes related to host immunity (Pinzón et al., 2015) and alter host metabolism (Kenkel, Meyer, \& Matz, 2013; Rodrigues \& Grottoli, 2007). Symbionts (family Symbiodiniaceae) expelled during bleaching produce elevated amounts of reactive oxygen species but are otherwise physiologically similar to healthy endosymbionts (Nielsen, Petrou, \& Gates, 2018). Sustained coral bleaching often leads to host mortality and subsequent shifts in the reef community structure (Harriott, 1985). For example, coral bleaching and mortality causes shifts in reef-fish assemblage structure and alters recruitment success (Booth \& Beretta, 2006; Richardson, Graham, Pratchett, Eurich, \& Hoey, 2018).

Coral mucus is a complex mixture of proteins, lipids, and carbohydrates that is produced by mucocytes in the coral epidermal layer and secreted by coral surface tissues (reviewed in Brown \& Bythell, 2005). Arabinose and glucose primarily compose the monosaccharide portion of coral mucus (Wild, Woyt, \& Huettel, 2005). Arabinose is likely a symbiont-specific contribution to coral mucus, as aposymbiotic, heterotrophic cold-water corals produce mucus nearly identical in composition to mucus from symbiotic warm-water corals, except for the presence of arabinose in the latter (Wild, Naumann, Niggl, \& Haas, 2010). Up to about half of the photosynthetically fixed carbon supplied by a coral's algal symbiont is expelled as mucus (Crossland, 1987; Crossland, Barnes, \& Borowitzka, 1980; Davies, 1984). This coral surface mucus layer acts as a defense against desiccation and pathogens (Shnit-Orland \& Kushmaro, 
51 2009), and is also released into the water column where it traps suspended particles and acts as

52 an energy source for benthic communities (Wild, Huettel, et al., 2004). Given the integral role of

53 photosynthetically fixed carbon in mucus production of most reef-building corals, it is predicted

54 that coral bleaching events will reduce mucus production and subsequently impact the flow of 55 energy throughout the reef ecosystem (Bythell \& Wild, 2011). However, one study has shown

56 that acroporid corals exposed to an experimental heat stress released almost twice as much

57 dissolved and particulate organic carbon relative to unchallenged controls (Niggl, Glas, Laforsch,

58 Mayr, \& Wild, 2009). One explanation for this finding is that increased mucus release in heat-

59 stressed corals augments defense against pathogens when other immune defense mechanisms

60 may be compromised by thermal challenge (Palmer, Bythell, \& Willis, 2010).

61 In the Florida Keys, annual mass bleaching events are predicted to begin by the mid-

62 century (Manzello, 2015). Currently, multiple anthropogenic factors including thermal stress,

63 increased storms, and disease outbreaks have led to a near $80 \%$ decline in reef cover in the

64 Florida Keys since the 1980s (Porter et al., 2001; Williams \& Miller, 2011; Williams, Miller, \&

65 Kramer, 2008). In particular, corals in the genus Acropora have faced some of the most dramatic

66 declines in this region (Greenstein, Curran, \& Pandolfi, 1998). The staghorn coral, Acropora

67 cervicornis, has been selected as a focal species for multiple active restoration programs, such as

68 the Coral Restoration Foundation, due to its relatively fast asexual growth through fragmentation

69 (Lirman et al., 2010). As restoration efforts aim to replenish stands of A. cervicornis, it is critical

70 to assess this species' greater role in coral reef ecosystem. This study aims to characterize coral

71 mucus release, composition, and antibacterial activity during acute thermal stress in $A$.

72 cervicornis as a reference to guide further research on the potential consequences of bleaching-

73 mediated mucus changes on the larger coral reef ecosystem. 
74

75 MATERIALS \& METHODS

76 Corals

77 Fifteen Acropora cervicornis genets ( $\mathrm{n}=3$ fragments per genet) were shipped from the Coral

78 Restoration Foundation (Key Largo, Florida USA, Project ID CRF-2016-021) on 7 September

792016 to the University of Texas at Austin. Upon arrival, corals were immediately tagged with

80 colored zip ties to uniquely identify each genet and allowed to recover for 12 days in artificial

81 seawater (ASW; 30-31 ppt) at $25^{\circ} \mathrm{C}$ under $12000 \mathrm{~K}$ LED lights on a $12 \mathrm{~h} / 12 \mathrm{~h}$ day/night cycle.

82 Corals were fed weekly with Ultimate Coral Food (Coral Frenzy, LLC).

83

84 Experimental conditions

85 Coral fragments were partitioned into experimental and control tanks. One genet (U10)

86 experienced mortality during the recovery period, so only one U10 fragment remained when the

87 experiment began. For all other genets, one fragment was placed in a control tank $\left(26^{\circ} \mathrm{C}\right)$ and one

88 fragment was placed in an experimental tank. Any remaining fragments from the shipment of $\mathrm{n}=$

893 per genet were retained in a holding tank, though many genets developed tissue loss or

90 experienced damage on a single fragment during shipping. The single remaining U10 fragment

91 was placed in the experimental tank. The temperature in the experimental tank was ramped from

$9226^{\circ} \mathrm{C}$ to $31^{\circ} \mathrm{C}$ over $33 \mathrm{~h}$. High summer temperature in the Florida Keys often reaches $31^{\circ} \mathrm{C}$

93 (Manzello, 2015). Therefore, a $31^{\circ} \mathrm{C}$ heat treatment was chosen to represent an ecologically

94 relevant stressor. 
95 After corals had been exposed to experimental conditions for four days, corals appeared visibly

96 pale relative to initial photographs and paired control fragments (Figure 1). At this time, the

97 temperature in the experimental tank was reduced to $26^{\circ} \mathrm{C}$ over $6 \mathrm{~h}$.

98

\section{Image analysis}

100 Prior to the experiment, photographs of each fragment were taken using a Nikon D5100 camera. 101 Images of the front and back of each fragment were taken using the same camera, settings, and

102 lighting each day of the experiment. Brightness values in images were measured for the front and 103 back sides of each fragment using image analysis software (ImageJ, Schneider, Rasband, \& 104 Eliceiri, 2012). Corals become brighter (paler) as their symbioses with pigmented algae break 105 down. Therefore, changes in coral brightness reflect changes in algal densities (Winters, 106 Holzman, Blekhman, Beer, \& Loya, 2009). A standard curve of brightness values was

107 constructed using standard Coral Health Charts that were included in each image. Briefly, 108 brightness (white value intensity measured in unitless values ranging 0-255) was measured for a 109 series of standard color cards (arbitrary values 1-6) in each photograph to construct a linear 110 curve of brightness to compare fragments. Brightness values were standardized to color cards to 111 normalize for any minor differences in lighting across days.

\section{Mucus collection}

114 After the experiment, each coral fragment was placed within a pre-weighed $50 \mathrm{~mL}$ conical tube 115 containing $5 \mathrm{~mL}$ ASW from the respective tank. Tubes were placed on their sides and secured to 116 a gently rocking incubator plate $\left(135 \mathrm{RPM}, 28^{\circ} \mathrm{C}\right)$ for 20 minutes, rotating the tubes every 5

117 minutes to ensure that all sides of the coral fragment were submerged in water. After rocking, 
118 fragments were inverted dry above the liquid in the conical for 20 minutes and lightly

119 centrifuged (200 RPM) for 2 minutes to pull down mucus adhering to the surface of the coral,

120 modified from (Wild, Huettel, et al., 2004). The volume and mass of mucus from each fragment

121 was measured and stored at $-80^{\circ} \mathrm{C}$. Coral fragments were returned to their tanks. The mucus

122 collection procedure was repeated six days later, exactly as described above. During mucus

123 collection, algal cells were clearly visible in some samples. All mucus aliquots were briefly

124 centrifuged at $3500 \mathrm{~g}$ for 2 minutes to sediment the algal pellet and decant algal cell-free mucus

125 before the experiments described below.

126

127 Mucus composition

128 Total protein was measured following the Coomassie (Bradford) Protein Assay Kit (Thermo

129 Scientific, Waltham, MA, USA). Total carbohydrate was measured using the Total Carbohydrate

130 Quantification Assay Kit (Abcam, Cambridge, UK). Total lipids were extracted and the dry mass

131 of each mucus sample were measured. A standard curve was prepared using reagent grade

132 cholesterol in a 2:1 chloroform:methanol mixture and an aliquot of 2:1 chloroform:methanol was

133 added to each sample tube. After mixing, the solvent was evaporated from all standard and

134 sample tubes on a heat block at $90^{\circ} \mathrm{C}$. Concentrated sulfuric acid was added to each tube, then

135 incubated at $90^{\circ} \mathrm{C}$ for 20 minutes. Samples were cooled, then plated in triplicate into wells of a

136 96-well plate. Background absorbance was measured at $540 \mathrm{~nm}$. After incubating each sample

137 with $50 \mu \mathrm{L}$ of vanillin-phosphoric acid for 10 minutes, absorbance was measured again at 540

$138 \mathrm{~nm}$. The concentrations of protein, carbohydrate, and lipid in the mucus were estimated using

139 standard curves constructed by measuring absorbance for known concentrations of protein, 
140 carbohydrate and lipids, per manufacturer's recommendations. All measurements were

141 normalized to the volume of mucus expelled and the surface area of the fragment.

142

143 Antibacterial activity

144 Cultures of laboratory E. coli (K-12) were grown overnight in Luria broth (LB), then washed

145 twice in sterile ASW to remove remaining culture media. Coral mucus $(140 \mu \mathrm{L})$ and washed $E$.

146 coli culture $(60 \mu \mathrm{L})$ was added to triplicate wells in 96 -well plates. The covered plates were

147 incubated at $37^{\circ} \mathrm{C}$ for $12 \mathrm{~h}$. Every 30 minutes the plate was shaken and the absorbance at $600 \mathrm{~nm}$

148 was measured. The plates were completely dry by the end of the incubation, so only the first $5 \mathrm{~h}$,

149 the latest time at which we observed liquid in the wells, are included in these analyses. Control

150 wells included bacteria in LB or coral mucus without added bacteria to demonstrate bacterial

151 growth or quantify endogenous mucus bacteria, respectively.

152

153 Coral surface area

154 Fragment surface area was estimated using a 3D scanner and accompanying ScanStudioPro

155 software (NextEngine, Santa Monica, CA, USA). Each scan was completed using a 360 degree

156 scan with 16 divisions and 10,000 points/inch ${ }^{2}$. Scans were then trimmed, polished to fill holes,

157 fused and then surface area was estimated based on a size standard.

158

159 Real-time quantitative PCR

160 The forward primer 5'-TCTGTACGCCAACACTGTGCTT-3' and reverse primer 5'-

161 AGTGATGCCAAGATGGAGCCT-3' was used to amplify the Acropora cervicornis actin

162 sequence as developed in (Winter, 2017). The forward primer 5'- 
163

164

165

166

167

168

169

170

171

172

173

174

175

176

177

178

179

180

181

182

183

184

185

GTGAATTGCAGAACTCCGTG-3' and reverse primer 5'-CCTCCGCTTACTTATATGCTT-3'

was used to amplify the Symbiodiniaceae ITS2 sequence. Primer pair specificity was verified by gel electrophoresis and melt curve analysis of the amplification product obtained with $A$.

cervicornis holobiont DNA. Primer efficiencies were determined by amplifying a series of four-

fold dilutions of $A$. cervicornis holobiont DNA and analyzing the results using PrimEff function

in the MCMC.qpcr package (Matz, Wright, \& Scott, 2013) in R. Briefly, $\mathrm{C}_{\mathrm{T}}$ (threshold cycle)

results were plotted as CT vs. $\log _{2}[\mathrm{DNA}]$, and amplification efficiencies (amplification factor per cycle) of each primer pair were derived from the slope of the regression using formula:

efficiency $=2-(1 /$ slope $)$ (Pfaffl, 2001).

Mucus aliquots were centrifuged to remove any cell debris. A $14 \mu \mathrm{L}$ aliquot of coral mucus was combined with SYBR Green PCR Master Mix (Applied Biosystems), 1.5 $\mu \mathrm{M}$ forward and reverse primers, and water. The Roche LightCycler 480 system was used to carry out the PCR protocol $\left(95^{\circ} \mathrm{C}\right.$ for 40 seconds, then 40 cycles of $60^{\circ} \mathrm{C}$ for 1 minute and $72^{\circ} \mathrm{C}$ for 1 minute) and detect the fluorescence signal.

\section{Statistics}

All statistical analyses were performed in R (3.4.0, R Core Team, 2016)). Bayesian models implemented using the MCMCglmm package (Hadfield, 2010) was used to explain variation in coral color and mucus composition, with treatment as a fixed effect and genotype as a random effect under a Gaussian distribution for coral color and metabolic assays and a Poisson distribution for marker gene counts. A nonlinear mixed-effects model followed by ANOVA was implemented using the nlme package (Pinheiro, Bates, DebRoy, \& Sarkar, 2017) was used for time-series analysis of antibacterial activity, with time, treatment, and their interaction as fixed 
186 effects and plate well as a random effect. Experimental data and R scripts are included as

187 Supplemental Data S1 and S2, respectively. Data and scripts can also be accessed on GitHub:

188 https://github.com/rachelwright8/bleached_coral_mucus.

189

190

191

192

193

194

195

196

197

198

199

200

201

202

203

204

205

206

207

208

\section{RESULTS}

\section{Coral bleaching and mucus collection}

Corals from both treatments produced similar amounts of mucus by volume $(\beta=0.01, p=0.25$, Figure $2 \mathrm{~A})$ and mass $(\beta=0.14, p=0.27$, Figure $2 \mathrm{~B})$. After a six-day recovery period, corals in both treatments produced significantly less mucus by volume $(\beta=-0.14, p<0.001$, Figure $2 \mathrm{~A})$ and mass $(\beta=-1.1, p<0.001$, Figure 2B) compared to the first time point. After four days in the experimental treatment at $31^{\circ} \mathrm{C}$, corals paled significantly compared to corals in the control condition $(\beta=-1.16, p<0.001$, Figure $3 \mathrm{~A})$.

\section{Mucus biochemistry}

The mucus produced by heat-stressed fragments contained significantly more total protein $(\beta=$ $2.1, p<0.001$, Figure 3B) and total lipid $(\beta=15.7, p=0.02$, Figure $3 \mathrm{C})$. There was also a slight increase in carbohydrate content in mucus from heat-stressed corals, though this difference was not significant $(\beta=0.64, p=0.10$, Figure 3D).

\section{Mucus antibacterial activity}

Antibacterial activity increased in thermally stressed corals from the experimental treatment relative to healthy corals (likelihood ratio $=100, p<0.001$, Figure 4). Optical density at $600 \mathrm{~nm}$ $\left(\mathrm{OD}_{600}\right)$, an absorbance measure that reflects bacterial density, decreased throughout the 
209 incubation period in all mucus samples. However, bacterial density declined significantly faster

210 in mucus samples from heat-stressed corals. Bacterial density remained low throughout the

211 sampling time period in negative control samples, which contained mucus from control corals

212 with no added bacteria, suggesting that decreases in observed bacterial density were due to

213 elimination of the experimentally added E. coli (Supplementary Figure 1). Positive control wells

214 that contained E. coli in growth media with no coral mucus increased in OD, showing that the

215 bacteria were alive and capable of growth under the experimental conditions (Supplementary

216 Figure 1).

217

218 Presence of host and symbiont DNA in mucus

219 Real-time quantitative PCR (qPCR) was performed to determine the relative abundances of 220 coral- and symbiont-derived marker gene copies present in the mucus released by healthy and

221 heat-stressed corals. Primers were designed to target a coral-specific actin gene and the

222 Symbiodiniaceae ITS2 region. Presumably, copies of the coral-specific actin gene would

223 represent lysed coral cells, while copies of the ITS2 region would represent material released

224 from Symbiodiniaceae cells in the mucus. We did not detect any ITS2 sequences in the mucus of

225 unchallenged corals (Figure 5). Mucus released by heat-stressed coral fragments contained

226 significantly more marker gene copies of both coral-derived $(95 \%$ credible interval $(\mathrm{CI})=1.6-$

$2274.6, \mathrm{p}=0.001)$ and symbiont-derived sequences $(95 \% \mathrm{CI}=4.3-25.7, \mathrm{p}<0.001$, Figure 5$)$.

228

229 DISCUSSION

230 Coral mucus stores take a long time to replenish. 
231 Mucus volumes released from both control and heat-stressed fragments during the initial 232 collection $\left(0.18 \pm 0.04 \mathrm{~mL} / \mathrm{cm}^{2}\right.$, or about $\left.1.8 \mathrm{~L} / \mathrm{m}^{2}\right)$ are consistent with daily mucus release 233 values previously reported for submerged acroporid corals $\left(1.7 \mathrm{~L} / \mathrm{m}^{2}\right.$ in Wild, Huettel, et al., 234 2004) . However, following a six-day recovery period, less than half of the original mucus 235 volume was collected from both control and heat-stressed fragments $\left(0.18 \pm 0.04 \mathrm{~mL} / \mathrm{cm}^{2}\right.$ initial 236 collection $v s .0 .08 \pm 0.02 \mathrm{~mL} / \mathrm{cm}^{2}$ post-recovery, $p_{\mathrm{MCMCglmm}}<0.001$, Figure $2 \mathrm{~A}$ ), suggesting that 237 mucus stores were not completely replenished to the original volume in this amount of time. The 238 methods used in this study to extract mucus left the coral nubbins completely dry. Therefore, the 239 results presented here represent the total volume of stored mucus at the time of collection, which 240 may not correspond directly to daily mucus release in natural settings. These results emphasize

241 the importance of measuring mucus release over time to confidently estimate daily release rates 242 and predict daily energetic flow throughout the reef ecosystem.

244 Stressed corals produce mucus high in protein and lipid.

245 We found no difference in the quantity of mucus produced by stressed corals compared to

246 healthy corals after four days of heat stress or after a six-day recovery period (Figure 2),

247 suggesting that the quantity of mucus produced by a coral is relatively unaffected by thermal 248 stress and that mucus stores cannot be replenished within a week. Given the energetic cost of 249 producing mucus (Riegl \& Branch, 1995), it is reasonable to predict that corals with low 250 densities of autotrophic symbionts would produce less, or lower nutritional quality, mucus than 251 healthy corals. These findings of enhanced protein and lipid content in mucus from heat-stressed 252 corals relative to mucus produced by healthy corals (Figure 3) support a previous study that 253 found increased organic carbon release by thermally stressed corals (Niggl et al., 2009). 
254 Symbiodiniaceae store reserve energy as lipid droplets and starch granules that are translocated

255 from the algal membrane to coral cells in a healthy coral-algae symbiotic relationship (Patton \&

256 Burris, 1983). We observed a pellet of algal cells in the mucus of thermally stressed corals, but

257 not in mucus produced by healthy corals. Though algal cells were pelleted and removed from all

258 mucus collections, extracellular lipid droplets would remain in the mucus and could represent a

259 potential explanation for the increased abundance of lipids in mucus from stressed corals.

260 Likewise, proteins and lipids released from damaged Symbiodiniaceae and host cells would also

261 be present in the mucus of stressed corals. This particular possibility is supported by finding both

262 coral and Symbiodiniaceae DNA in the mucus of stressed corals (Figure 5). Future studies

263 should measure long-term effects of bleaching to determine the duration of this observed

264 enrichment in coral mucus quality following thermal stress.

265

This short-term enrichment in nutrition could invoke shifts in trophic interactions and

266 density dependent foraging behavior in coralivorous fish and invertebrates. In the Florida Keys,

267 previous studies have observed increased predation intensity by corallivorous fishes and

268 invertebrates as coral cover declines (Baums, Miller, \& Szmant, 2003; Burkepile, 2012). In

269 addition, there is established prey preference asymmetries in the Caribbean, where A. cervicornis

270 is already the preferred prey of a corallivorous gastropod (Johnston \& Miller, 2014). Our results

271 implicate that as heat-stressed corals release more nutrients into their mucus, this may drive

272 stronger predation pressure, at least in bursts associated with the bleaching event itself. This may

273 only maintain a benefit to higher trophic levels at very short time scales, as predation on coral

274 reef dwelling fish is higher when they reside in bleached corals (Coker, Pratchett, \& Munday,

275 2009) and corallivorous fish are well known to suffer population declines in response to coral

276 bleaching (Pratchett, Thompson, Hoey, Cowman, \& Wilson, 2018). Therefore, future studies 
277 should investigate how bleaching impacts predator-prey dynamics between corals and

278 corallivorous fish and invertebrates.

279

280 Stressed corals produce mucus with high antibacterial activity.

281 This study found that mucus collected from stressed coral fragments eliminated bacteria faster

282 than mucus from healthy fragments from matched genets (Figure 4). Antibacterial activity of

283 coral mucus is attributed to antimicrobial substances produced by commensal microbes living on

284 the coral surface (Nissimov, Rosenberg, \& Munn, 2009; Shnit-Orland \& Kushmaro, 2009). A

285 previous study of mucus collected from A. palmata during a summer bleaching event in the

286 Florida Keys found that mucus from bleached corals lacked antibiotic properties normally found

287 in healthy coral mucus (Ritchie, 2006). The difference in findings between this study and the

288 investigation of antibiotic activity in naturally bleached corals could be attributed to the timing of

289 collections. Mucus in this study was collected as soon as corals became pale, whereas the

290 previous study collected mucus after corals in the Florida Keys had been experiencing high

291 levels of thermal stress and bleaching for about a month according to NOAA reports of the

292 thermal stress event (Eakin et al., 2010). Long-term thermal stress is known to promote coral

293 disease by altering bacterial pathogenicity and host susceptibility (Bruno et al., 2007; Maynard et

294 al., 2015). In our short-term bleaching conditions, the increased protein and lipid content in the

295 mucus (Figure 3B-C) may have temporarily improved the antibacterial activity of commensal

296 microbes that exist in the coral mucus (Krediet, Ritchie, Paul, \& Teplitski, 2013). Though the

297 mechanism is unclear, Symbiodiniaceae do appear to play a role in a coral's ability to manage

298 immune stress and regulate microbial communities (Littman, Bourne, \& Willis, 2010; Wright et

299 al., 2017). 
301 mucus supports the growth of bacterial species found on corals (Wild, Rasheed, et al., 2004), 302 such as Pseudoalteromonas and Vibrio spp. (Allers, Niesner, Wild, \& Pernthaler, 2008). Both 303 Pseudoalteromonas and Vibrio are commonly observed in corals, though they are usually 304 associated with coral stress and disease suggesting that these bacteria employ mechanisms to 305 resist antimicrobial properties of coral mucus (Ritchie, 2006) that our lab E. coli strain, which 306 was naïve to coral mucus, presumably lacks. This difference in bacterial species could explain 307 the discrepancy in findings. Additionally, the previous experiments measured bacterial growth 308 over $40-50 \mathrm{~h}$. It is possible that we would have found similar results had we measured bacterial 309 growth beyond $5 \mathrm{~h}$.

\section{CONCLUSIONS}

312 Our results show that thermal stress does not significantly affect the volume of mucus produced 313 by $A$. cervicornis immediately following a bleaching event. Stressed corals produced mucus with

314 higher protein content, higher lipid content, and increased antibacterial activity relative to 315 unstressed controls. Additional lipids and proteins likely come from Symbiodiniaceae and host 316 cells damaged during bleaching rather than from additional investment by the coral host. Short317 term nutritional enrichments of mucus released from bleaching corals could promote growth of 318 heterotrophic microbes at the lowest trophic levels of marine ecosystems and thus cause large319 scale shifts in a reef's nutrient cycle. Changes in the nutritional composition and antibacterial 320 properties of the mucus should influence coral-associated microbes that contribute to coral 321 disease susceptibility. Future experiments should investigate longer-term effects of thermal stress 
322 on mucus production and content to further investigate reef-wide consequences of coral 323 bleaching.

324

325 


\section{ACKNOWLEDGEMENTS}

327 We thank the Coral Reef Foundation for providing coral specimen and Sarah Davies for 328 measuring coral surface areas.

329 
330

331

332

333

334

335

336

337

338

339

340

341

342

343

344

345

346

347

348

349

350

351

352

\section{REFERENCES}

Allers, E., Niesner, C., Wild, C., \& Pernthaler, J. (2008). Microbes enriched in seawater after addition of coral mucus. Applied and Environmental Microbiology, 74(10), 3274-3278. https://doi.org/10.1128/AEM.01870-07

Baums, I. B., Miller, M. W., \& Szmant, A. M. (2003). Ecology of a corallivorous gastropod, Coralliophila abbreviata, on two scleractinian hosts, I: Population structure of snails and corals. Marine Biology, 142(6), 1083-1091. https://doi.org/10.1007/s00227-003-1024-9

Booth, D. J., \& Beretta, G. A. (2006). <825 - Booth \& Beretta Bleaching and Fish.pdf>, 245, $205-212$.

Brown, B., \& Bythell, J. (2005). Perspectives on mucus secretion in reef corals. Marine Ecology Progress Series, 296, 291-309.

Bruno, J. F., Selig, E. R., Casey, K. S., Page, C. A., Willis, B. L., Harvell, C. D., ... Melendy, A. M. (2007). Thermal stress and coral cover as drivers of coral disease outbreaks. PLoS Biology, 5(6), 1220-1227. https://doi.org/10.1371/journal.pbio.0050124

Burkepile, D. E. (2012). Context-dependent corallivory by parrotfishes in a Caribbean reef ecosystem. Coral Reefs, 31(1), 111-120. https://doi.org/10.1007/s00338-011-0824-5

Bythell, J. C., \& Wild, C. (2011). Biology and ecology of coral mucus release. Journal of Experimental Marine Biology and Ecology, 408(1-2), 88-93. https://doi.org/10.1016/j.jembe.2011.07.028

Coker, D. J., Pratchett, M. S., \& Munday, P. L. (2009). Coral bleaching and habitat degradation increase susceptibility to predation for coral-dwelling fishes. Behavioral Ecology, 20(6), 1204-1210. https://doi.org/10.1093/beheco/arp113

Crossland, C. J. (1987). In situ release of mucus and DOC-lipid from the corals Acropora 

variabilis and Stylophora pistillata in different light regimes. Coral Reefs, 6(1), 35-42.

354 Crossland, C. J., Barnes, D. J., \& Borowitzka, M. a. (1980). Diurnal lipid and mucus production 355 in the staghorn coral Acropora acuminata. Marine Biology, 60(2-3), 81-90.

356 https://doi.org/10.1007/BF00389151

357 Davies, P. S. (1984). The role of zooxanthellae in the nutritional energy requirements of 358 Pocillopora eydouxi. Coral Reefs, 2(4), 181-186. https://doi.org/10.1007/BF00263571 359 Eakin, C. M., Morgan, J. A., Heron, S. F., Smith, T. B., Liu, G., Alvarez-Filip, L., ... Yusuf, Y. 360 (2010). Caribbean corals in crisis: Record thermal stress, bleaching, and mortality in 2005. $361 \quad P L o S O N E, 5(11)$. https://doi.org/10.1371/journal.pone.0013969

362 Greenstein, B. J., Curran, H. A., \& Pandolfi, J. M. (1998). Shifting ecological baselines and the 363 demise of Acropora cervicornis in the western North Atlantic and Caribbean Province: A 364 Pleistocene perspective. Coral Reefs, 17(3), 249-261.

365 https://doi.org/10.1007/s003380050125

366 Hadfield, J. D. (2010). MCMC methods for multi-response generalized linear mixed models: the 367 MCMCglmm R package. Journal of Statistical Software, 33(2), 1-22.

368 https://doi.org/10.1002/ana.22635

369 Harriott, V. J. (1985). During a Mass Bleaching Event. Marine Ecology Progress Series, 21(1), $370 \quad$ 81-88. https://doi.org/10.3354/meps021081

371 Hughes, T. P., Kerry, J. T., Baird, A. H., Connolly, S. R., Dietzel, A., Eakin, C. M., ... Torda, G. 372 (2018). Global warming transforms coral reef assemblages. Nature, 556, 492-496. 373 https://doi.org/10.1038/s41586-018-0041-2

374 Johnston, L., \& Miller, M. W. (2014). Negative indirect effects of neighbors on imperiled 375 scleractinian corals. Coral Reefs, 33(4), 1047-1056. https://doi.org/10.1007/s00338-014- 
377

378

379

380

381

382

383

384

385

386

387

388

389

390

391

392

393

394

395

396

397

398

Kenkel, C. D., Meyer, E., \& Matz, M. V. (2013). Gene expression under chronic heat stress in populations of the mustard hill coral (Porites astreoides) from different thermal environments. Molecular Ecology, 22(16), 4322-4334. https://doi.org/10.1111/mec.12390

Krediet, C. J., Ritchie, K. B., Paul, V. J., \& Teplitski, M. (2013). Coral-associated microorganisms and their roles in promoting coral health and thwarting diseases. Proceedings. Biological Sciences / The Royal Society, 280(1755), 20122328. https://doi.org/10.1098/rspb.2012.2328

Lirman, D., Thyberg, T., Herlan, J., Hill, C., Young-Lahiff, C., Schopmeyer, S., ... Drury, C. (2010). Propagation of the threatened staghorn coral Acropora cervicornis: Methods to minimize the impacts of fragment collection and maximize production. Coral Reefs, 29(3), 729-735. https://doi.org/10.1007/s00338-010-0621-6

Littman, R. A., Bourne, D. G., \& Willis, B. L. (2010). Responses of coral-associated bacterial communities to heat stress differ with Symbiodinium type on the same coral host. Molecular Ecology, 19(9), 1978-1990. https://doi.org/10.1111/j.1365-294X.2010.04620.x

Manzello, D. P. (2015). Rapid Recent Warming of Coral Reefs in the Florida Keys. Scientific Reports, 5, 1-10. https://doi.org/10.1038/srep16762

Matz, M. V, Wright, R. M., \& Scott, J. G. (2013). No Control Genes Required: Bayesian Analysis of qRT-PCR Data. PloS ONE, 8(8), e71448. https://doi.org/10.1371/journal.pone.0071448

Maynard, J., van Hooidonk, R., Eakin, C. M., Puotinen, M., Garren, M., Williams, G., ... Harvell, C. D. (2015). Projections of climate conditions that increase coral disease susceptibility and pathogen abundance and virulence. Nature Climate Change, 5(May), 
400

401

402

403

404

405

406

407

408

409

410

411

412

413

414

415

416

417

418

419

420

421

Nielsen, D. A., Petrou, K., \& Gates, R. D. (2018). Coral bleaching from a single cell perspective. ISME Journal, 1-10. https://doi.org/10.1038/s41396-018-0080-6

Niggl, W., Glas, M. S., Laforsch, C., Mayr, C., \& Wild, C. (2009). First evidence of coral bleaching stimulating organic matter release by reef corals. Proceedings of the 11th International Coral Reef Symposium, (July), 905-910.

Nissimov, J., Rosenberg, E., \& Munn, C. B. (2009). Antimicrobial properties of resident coral mucus bacteria of Oculina patagonica. FEMS Microbiology Letters, 292(2), 210-215. https://doi.org/10.1111/j.1574-6968.2009.01490.x

Palmer, C. V, Bythell, J. C., \& Willis, B. L. (2010). Levels of immunity parameters underpin bleaching and disease susceptibility of reef corals. Federation of American Societies for Experimental Biology, 24(6), 1935-1946. https://doi.org/10.1096/fj.09-152447

Patton, J. S., \& Burris, J. E. (1983). Lipid synthesis and extrusion by freshly isolated zooxanthellae (symbiotic algae). Marine Biology, 75(2-3), 131-136. https://doi.org/10.1007/BF00405995

Pfaffl, M. W. (2001). A new mathematical model for relative quantification in real-time RTPCR. Nucleic Acids Research, 29(9), e45. Retrieved from http:/www.ncbi.nlm.nih.gov/pmc/articles/PMC55695/

Pinheiro, J., Bates, D., DebRoy, S., \& Sarkar, D. (2017). nlme: Linear and Nonlinear Mixed Effects Models.

Pinzón, J. H., Kamel, B., Burge, C. A., Harvell, C. D., Medina, M., Weil, E., \& Mydlarz, L. D. (2015). Whole transcriptome analysis reveals changes in expression of immune-related genes during and after bleaching in a reef-building coral. Royal Society Open Science, 2. 
422 https://doi.org/140214

423 Porter, J. W., Dustan, P., Jaap, W. C., Patterson, K. L., Kosmynin, V., Meier, O. W., ... Parsons, 424 M. (2001). Patterns of spread of coral disease in the Florida Keys. Hydrobiologia, 460, 142524.

426 Pratchett, M., Thompson, C., Hoey, A., Cowman, P., \& Wilson, S. (2018). Effects of Coral 427 Bleaching and Coral Loss on the Structure and Function of Reef Fish Assemblages. In $428 \quad$ Coral Bleaching (pp. 265-293).

429 R Core Team. (2016). R: A language and environment for statistical computing. R Foundation 430 for Statistical Computing, Vienna, Austria. Retrieved from https:/www.r-project.org/ 431 Richardson, L. E., Graham, N. A. J., Pratchett, M. S., Eurich, J. G., \& Hoey, A. S. (2018). Mass 432 coral bleaching causes biotic homogenization of reef fish assemblages. Global Change 433 Biology, 24(7), 3117-3129. https://doi.org/10.1111/gcb.14119

434 Riegl, B., \& Branch, G. M. (1995). Effects of sediment on the energy budgets of four 435 scleractinian ( Bourne 1900 ) and five alcyonacean ( L amouroux 1816 ) corals. Journal of Experimental Marine Biology and Ecology, 186, 259-275. https://doi.org/10.1016/00220981(94)00164-9

Ritchie, K. (2006). Regulation of microbial populations by coral surface mucus and mucusassociated bacteria. Marine Ecology Progress Series, 322, 1-14.

Rodrigues, L. J., \& Grottoli, A. G. (2007). Energy reserves and metabolism as indicators of coral recovery from bleaching. Limnology and Oceanography, 52(5), 1874-1882. https://doi.org/10.4319/1o.2007.52.5.1874

444 Schneider, C., Rasband, W., \& Eliceiri, K. (2012). NIH Image to ImageJ: 25 years of image 
445

446

447

448

449

450

451

452

453

454

455

456

457

458

459

460

461

462

463

464

465

466

467

analysis. Nature Methods, 9(7), 671-675.

Shnit-Orland, M., \& Kushmaro, A. (2009). Coral mucus-associated bacteria: A possible first line of defense. FEMS Microbiology Ecology, 67(3), 371-380. https://doi.org/10.1111/j.15746941.2008.00644.x

Wild, C., Huettel, M., Klueter, A., Kremb, S. G., Rasheed, M. Y. M., \& Jørgensen, B. B. (2004). Coral mucus functions as an energy carrier and particle trap in the reef ecosystem. Nature, 428(6978), 66-70. https://doi.org/10.1038/nature02344

Wild, C., Naumann, M., Niggl, W., \& Haas, A. (2010). Carbohydrate composition of mucus released by scleractinian warm- and cold-water reef corals. Aquatic Biology, 10(1), 41-45. https://doi.org/10.3354/ab00269

Wild, C., Rasheed, M., Werner, U., Franke, U., Johnstone, R., \& Huettel, M. (2004). Degradation and mineralization of coral mucus in reef environments. Marine Ecology Progress Series, 267, 159-171. https://doi.org/10.3354/meps267159

Wild, C., Woyt, H., \& Huettel, M. (2005). Influence of coral mucus on nutrient fluxes in carbonate sands. Marine Ecology Progress Series, 287(June 2014), 87-98. https://doi.org/10.3354/meps287087

Williams, D. E., \& Miller, M. W. (2011). Attributing mortality among drivers of population decline in Acropora palmata in the Florida Keys (USA). Coral Reefs, 31(2), 369-382. https://doi.org/10.1007/s00338-011-0847-y

Williams, D. E., Miller, M. W., \& Kramer, K. L. (2008). Recruitment failure in Florida Keys Acropora palmata, a threatened Caribbean coral. Coral Reefs, 27(3), 697-705. https://doi.org/10.1007/s00338-008-0386-3

Winter, R. N. (2017). Environmental Controls on the Reassembly of Symbiodinium Communities 
468 in Reef Corals Following Perturbation: Implications for Reef Futures under Climate

469 Change. Retrieved from https://scholarlyrepository.miami.edu/oa_dissertations/1870

470 Winters, G., Holzman, R., Blekhman, a., Beer, S., \& Loya, Y. (2009). Photographic assessment

471 of coral chlorophyll contents: Implications for ecophysiological studies and coral

472 monitoring. Journal of Experimental Marine Biology and Ecology, 380(1-2), 25-35.

$473 \quad$ https://doi.org/10.1016/j.jembe.2009.09.004

474 Wright, R. M., Kenkel, C. D., Dunn, C. E., Shilling, E. N., Bay, L. K., \& Matz, M. V. (2017).

475 Intraspecific differences in molecular stress responses and coral pathobiome contribute to

476 mortality under bacterial challenge in Acropora millepora. Scientific Reports, 7(1).

$477 \quad$ https://doi.org/10.1038/s41598-017-02685-1

478 


\section{Figure 1}

Experimental design and representative coral image.

Corals were maintained in either $(\mathrm{A})$ control $\left(26^{\circ} \mathrm{C}\right)$ or $(\mathrm{B})$ experimental $\left(31^{\circ} \mathrm{C}\right)$ conditions for four days. Paling was observed for fragments in the experimental treatment, but not under control conditions. 
Acropora cervicornis
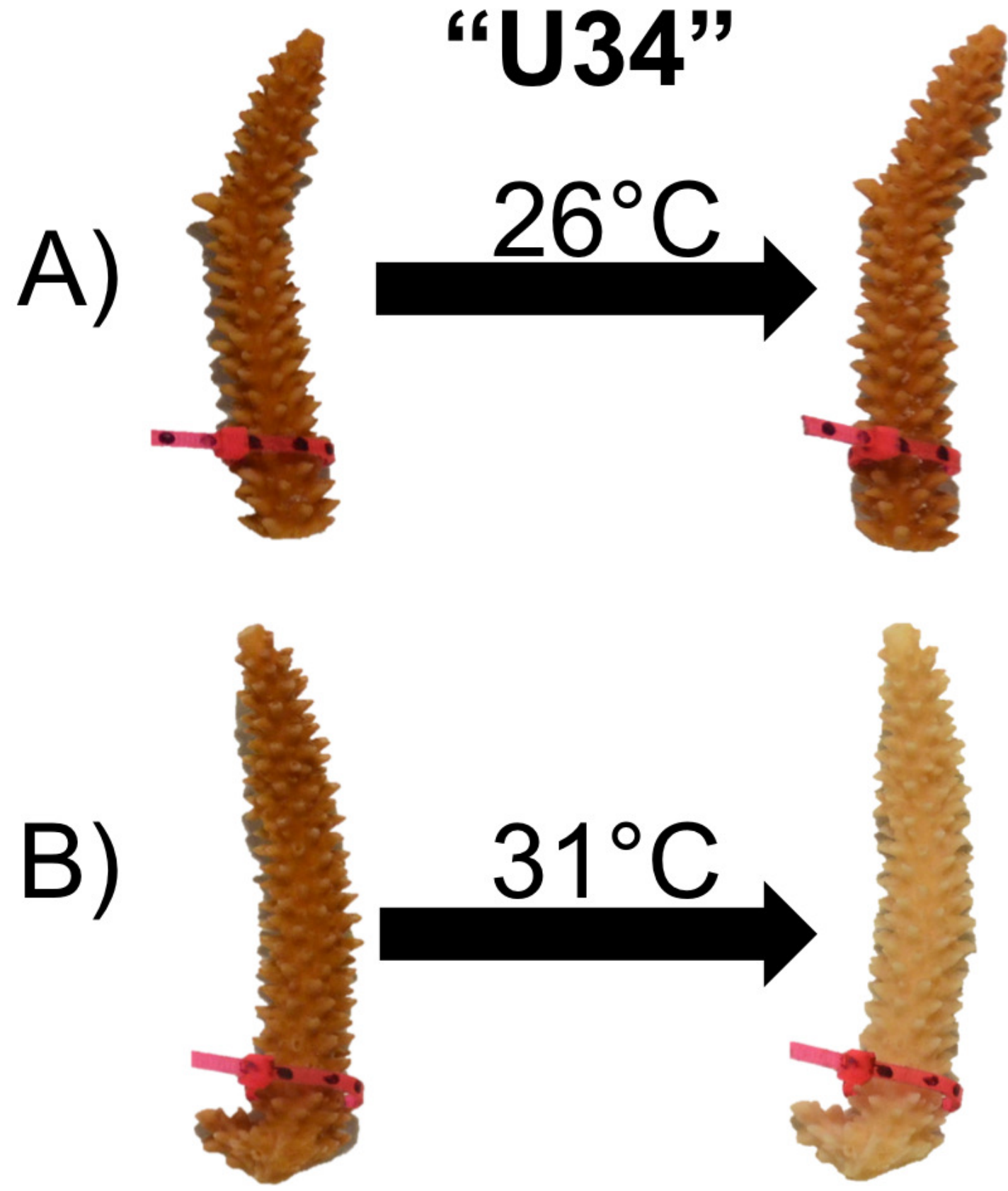

30 Sept 20163 Oct 2016 


\section{Figure 2}

Mucus production.

Mucus was collected immediately after paling was observed ("Initial") and six days after the challenged corals were returned to control conditions ("Recovery"). The volume (A) and mass

(B) of the recovered mucus was normalized to the surface area of the coral fragment. Red boxes represent fragments in control conditions; beige boxes represent heat-stressed fragments. Error bars represent standard error.
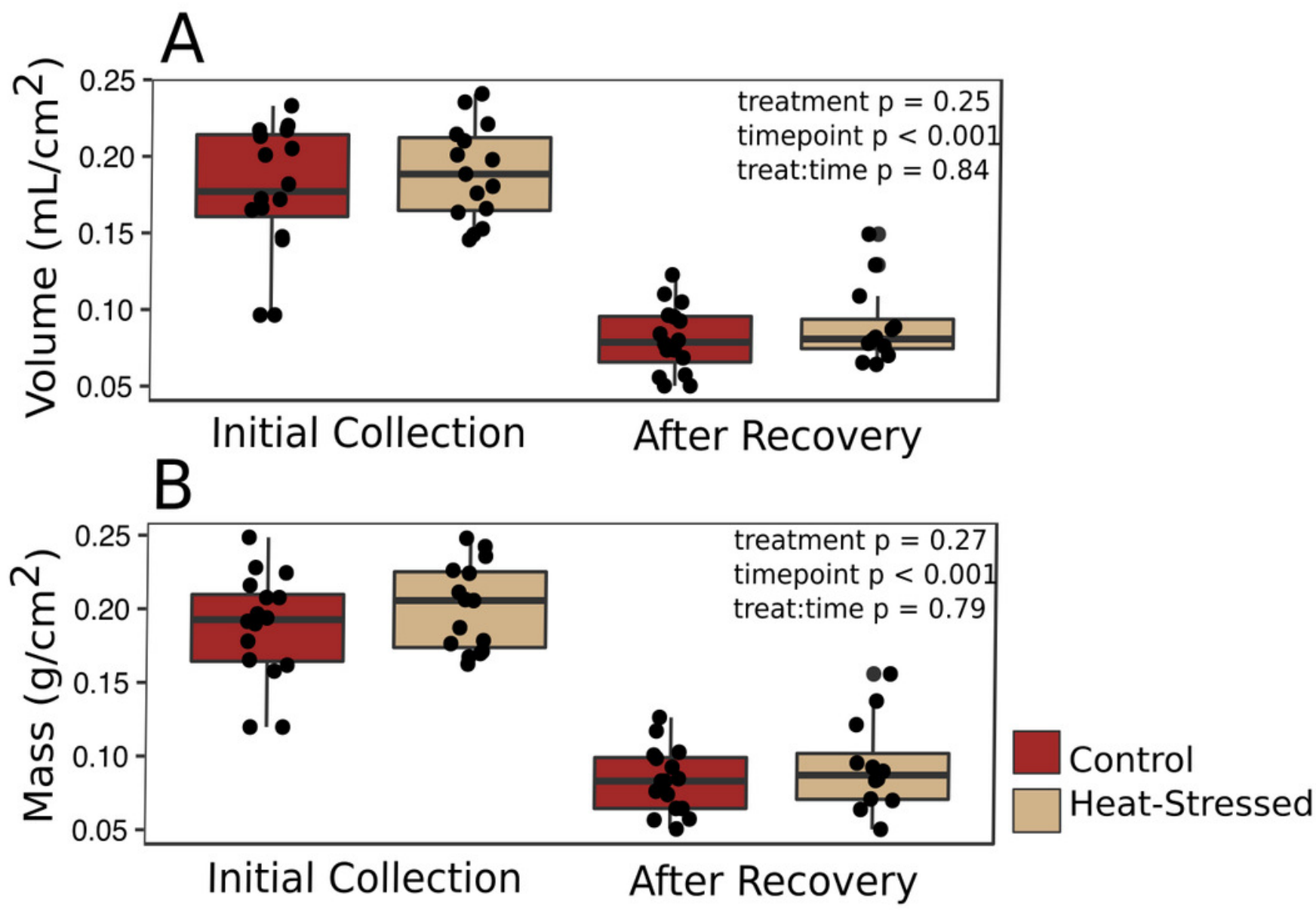


\section{Figure 3}

Effects of heat stress.

(A) Effect of treatment on coral color (decrease in color score indicates bleaching). (B-D) Effects on mucus composition: protein (B), in $\mathrm{mg} / \mathrm{cm}^{2}$ fragment surface area, and lipid (C) and carbohydrate (D), in $\mu \mathrm{g} / \mathrm{cm}^{2}$ fragment surface area. Red boxes represent fragments in control conditions; beige boxes represent heat-stressed fragments. Error bars represent standard error. 

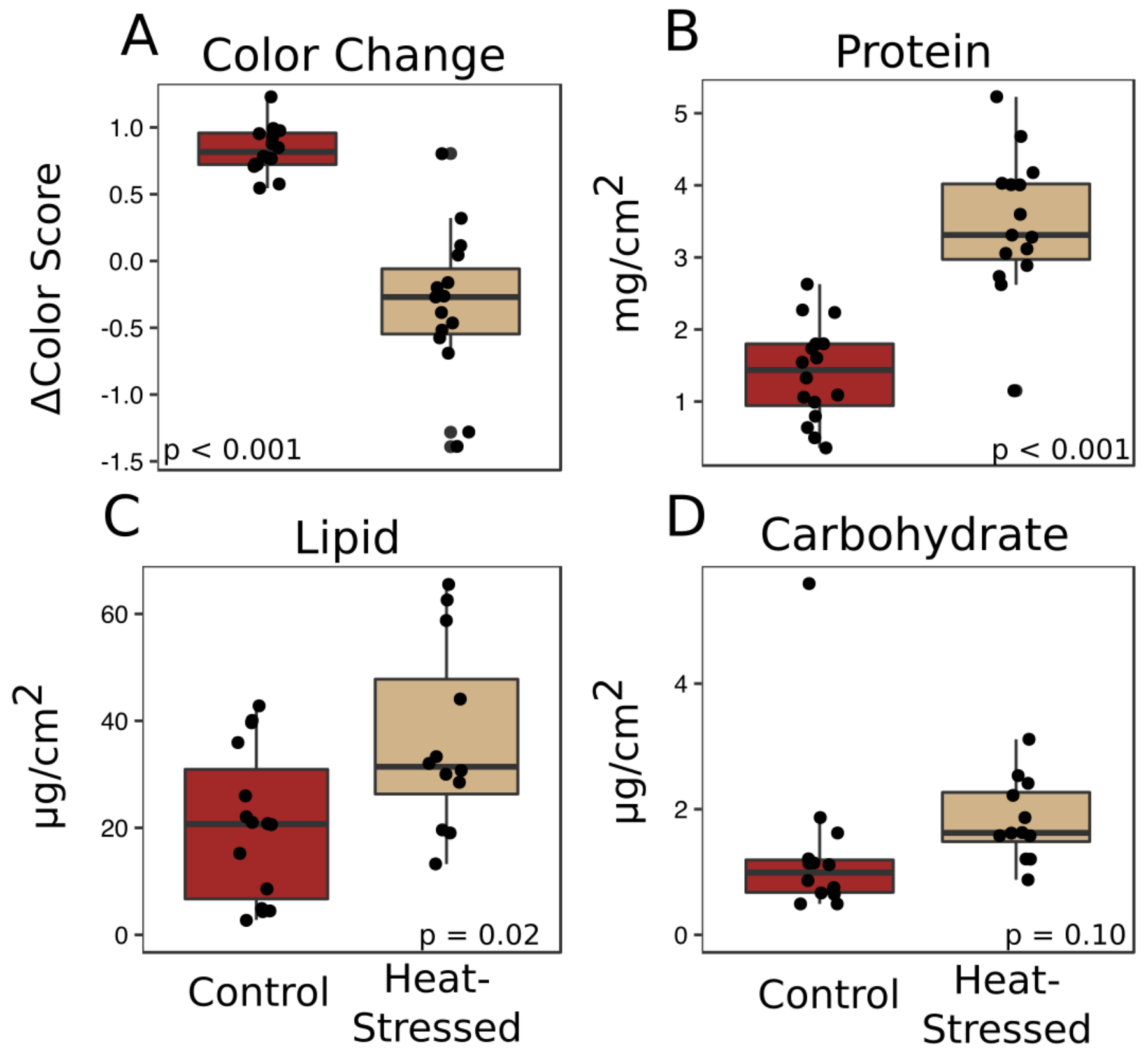
Figure 4

Antibacterial activity of coral mucus.

Optical density (OD) at $600 \mathrm{~nm}$ indicates the density of inoculated bacteria in coral mucus samples. Red lines represent fragments in control conditions; beige lines represent heatstressed fragments. Error bars represent standard error.

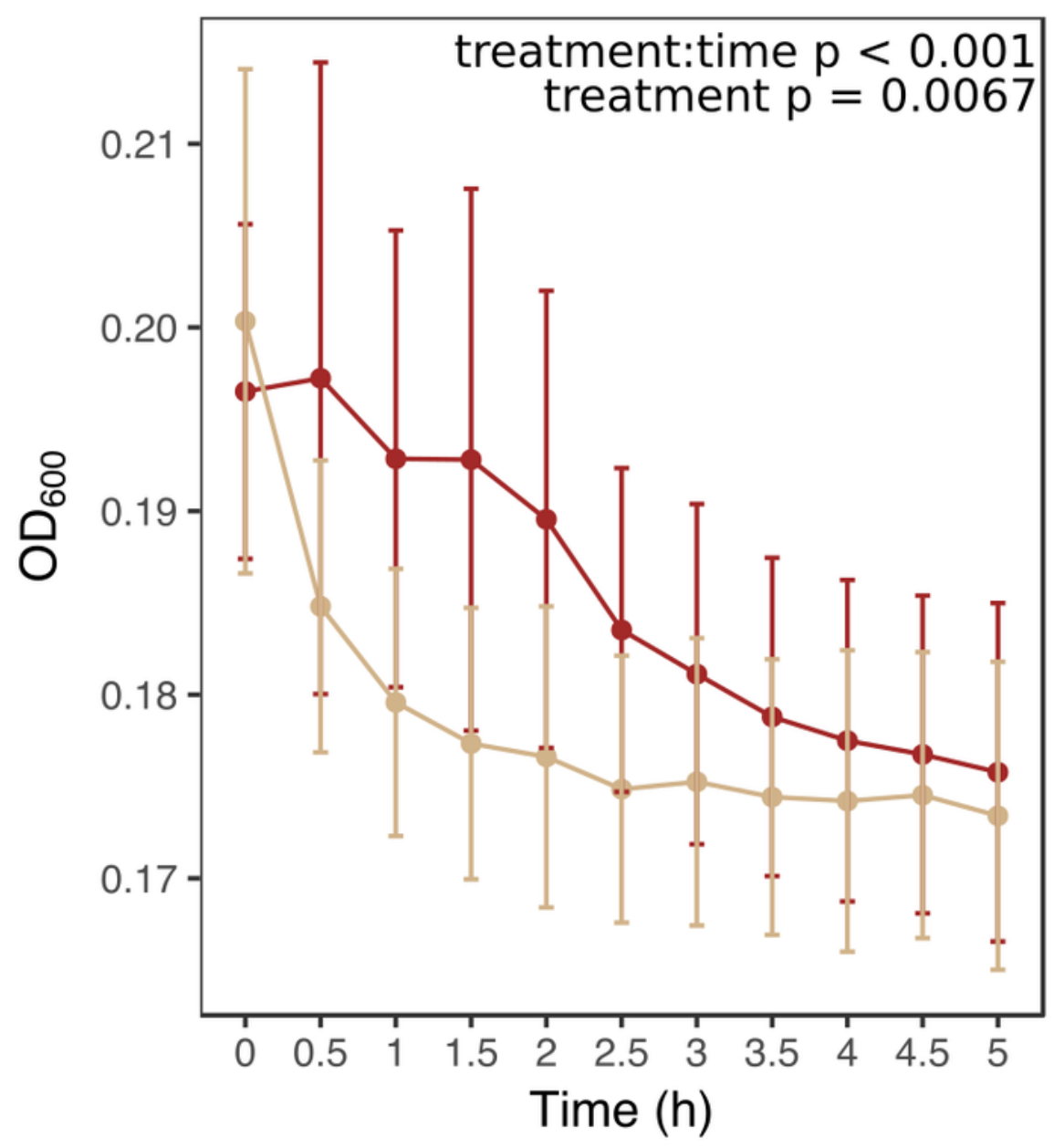


Figure 5

Symbiodiniaceae and coral DNA in mucus.

Real-time quantitative PCR detected A. cervicornis actin (A) or Symbiodiniaceae ITS2 (B) marker gene copies in the coral mucus of healthy and pale corals. Red boxes represent fragments in control conditions; beige boxes represent heat-stressed fragments. Error bars represent standard error.
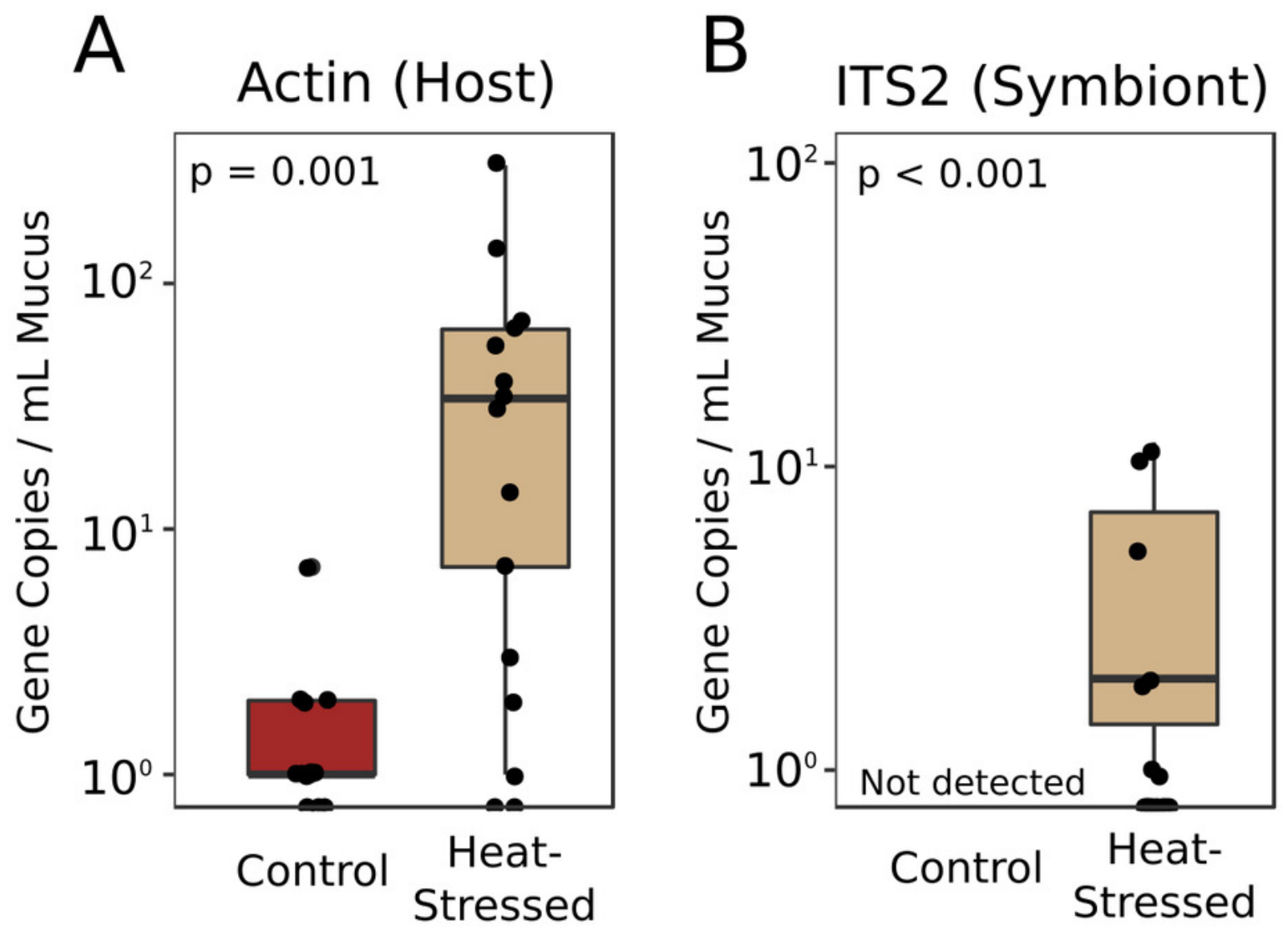